\title{
Streptococcus faecalis Chain Disruption
}

\author{
By M. R. SHAIKH* AND D. E. S. STEWART-TULL \\ Department of Microbiology, University of Glasgow, Alexander Stone Building, \\ Bearsden, Glasgow G6I I $Q H$
}

(Received 20 December 1974; revised I4 May 1975)

\section{INTRODUCTION}

Many Streptococci are characterized by the formation of long chains of cells. However, Streptococcus faecalis forms short chains of 4 to 6 cells or no chains at all, indicating that a cell-separating system must be active throughout the growth cycle. Although biochemically and serologically identical with typical $S$. faecalis, strain NCTC2400 forms long chains. Lominski, Cameron \& Wyllie (1958), using Suramin (Bayer 205), stimulated typical $S$. faecalis to grow with long chains which were broken down by filtrates of ordinary cultures.

Toennies et al. (196I) noted that the increasing speed of autolysis during exponential growth of $S$. faecalis corresponded to a decrease in average chain length of the cocci. Numerous other workers have also suggested that autolysins may be involved in cell separation (see for example Tomasz, I968; Chatterjee et al. 1969; Fan, 1970a, b; Soper \& Winter, 1973).

The autolysin in $S$. faecalis occurs in the region of the septum and of the most recently deposited wall, and is produced maximally during the period of exponential growth (Shockman, Pooley \& Thompson, 1967; Higgins, Pooley \& Shockman, 1970). It is an endo- $N$ acetylmuramidase which hydrolyses the $\beta$-I,4 bonds between $N$-acetylmuramic acid and $N$-acetylglucosamine (Shockman, Thompson \& Conover, 1967) and may be necessary for the growth and extension of the mucopeptide in the wall (Pooley \& Shockman, 1970).

This investigation examines the effect of supernatant fluids from short-chain cultures of $S$. faecalis on the long-chain variant $S$. faecalis NCTC2400.

\section{METHODS}

Short-chain Streptococcus faecalis strains 064 and Dunnet were isolated in the Department of Bacteriology and Immunology, Western Infirmary, Glasgow from the urine of patients suffering from urinary tract infections. Streptococcus faecalis NCTC2400, obtained from the National Collection of Type Cultures, London, grew spontaneously in long chains and was cultured in brain-heart infusion broth (Difco) for $18 \mathrm{~h}$ at $37^{\circ} \mathrm{C}$. The culture was centrifuged at $3600 \mathrm{rev} . / \mathrm{min}(2000 \mathrm{~g})$ for $20 \mathrm{~min}$ and the sediment was washed twice with sterile $\mathrm{NaCl}(0.15 \mathrm{M}, \mathrm{pH} 7.0)$ and finally resuspended in the same diluent to give an EEL nephelometer reading of $80.0 \%$. Prewarmed brain-heart infusion broth $\mathrm{pH} 7.4$ to 7.6 $(500 \mathrm{ml})$ was inoculated with $10 \mathrm{ml}$ of a $5 \mathrm{~h}$ culture of $S$. faecalis Dunnet or 064 and incubated for $\mathrm{I} 8 \mathrm{~h}$ at $37^{\circ} \mathrm{C}$. The culture was centrifuged at $3600 \mathrm{rev} . / \mathrm{min}(2000 \mathrm{~g})$ and the supernatant fraction $(\mathrm{SF})$ was retained. The SF ( $1.0 \mathrm{ml})$ was thoroughly mixed with $0.2 \mathrm{ml}$ of the long-chain suspension of $S$. faecalis NCTC2400 and incubated at $37^{\circ} \mathrm{C}$. At intervals from o min to $3 \mathrm{~h}$, the average chain length was determined microscopically and smears were stained to determine any change in the Gram reaction.

For the time lapse photomicrography, $0.02 \mathrm{ml}$ of SF was mixed with a loopful of the long-

* Present address: Department of Microbiology, University of Karachi, Karachi, Pakistan. 

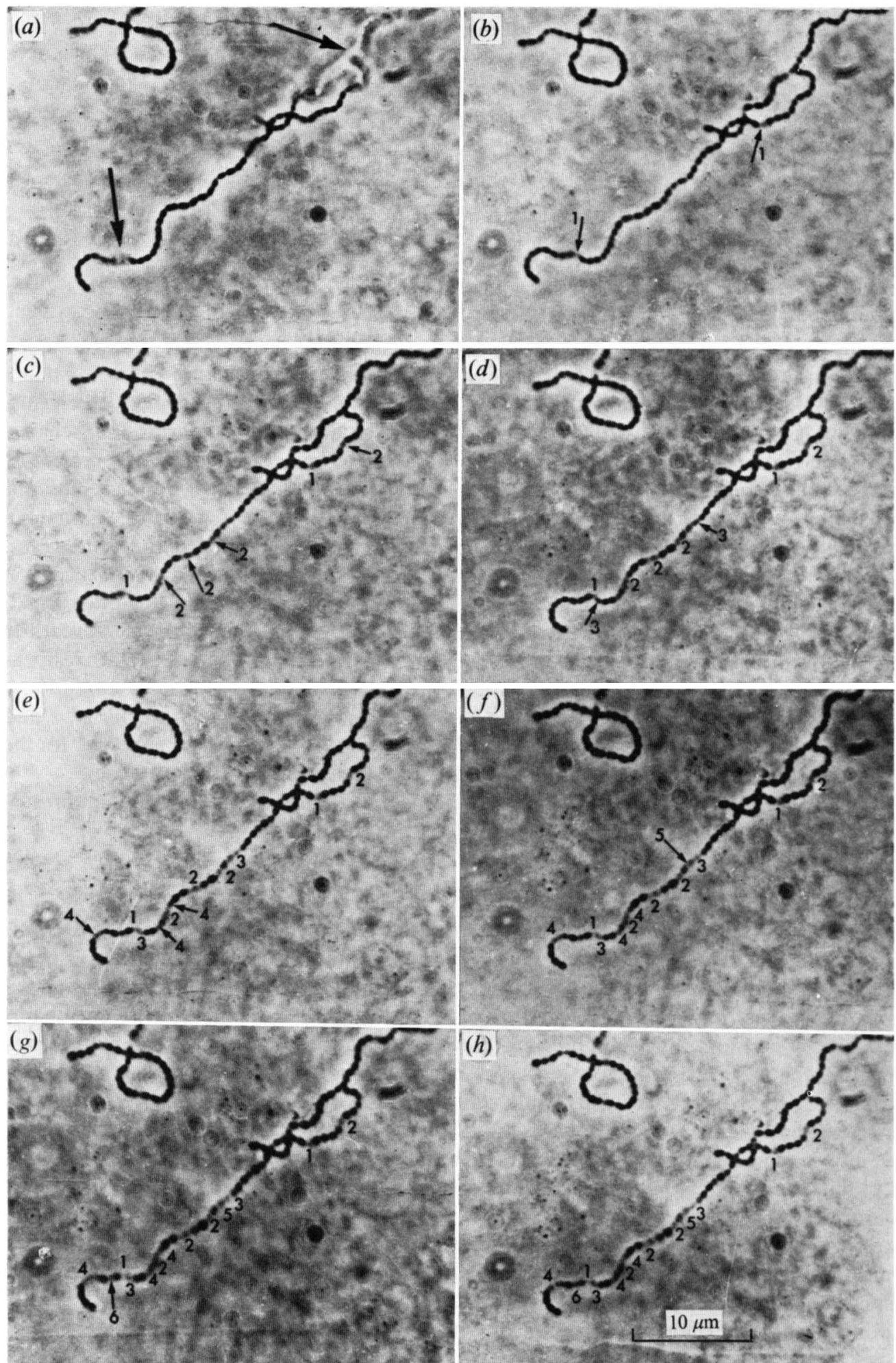

Fig. I. Time-lapse photomicrographs of chain disruption of $S$. faecalis NCTC2400 by the SF from $S$. faecalis 064: (a) $20 \mathrm{~min},($ b) $30 \mathrm{~min},(c) 40 \mathrm{~min},(d) 50 \mathrm{~min},(e) 60 \mathrm{~min},(f) 70 \mathrm{~min},(g) 80 \mathrm{~min},(h)$ the complete sequence of disruption after $90 \mathrm{~min}$. The sites and order of attack are shown by arrows and numbers. The heavy arrows in $(a)$ indicate non-alignment of the chain in the focused plane, and not chain disruption. 
chain suspension of $S$. faecalis NCTC2400 on a microsope slide and covered with a coverslip. The slides were incubated in a moist chamber at $37^{\circ} \mathrm{C}$ and examined at intervals to determine any alteration in chain length. To assist photomicrography, a drop of $0.2 \%$ Difco agarsolution was added to the mixture to minimize movement of the chains.

\section{RESULTS AND DISCUSSION}

The SF disrupted long chains (Io to 40 cells) of $S$. faecalis NCTC2400; I $\cdot 0 \mathrm{~h}$ after mixing, single cells, paired cells or 4 to 6 cell chains were found. Lysing cells in disrupting chains were also Gram-negative. No disruption of the long chains of cocci occurred if the SF was previously heated at $100{ }^{\circ} \mathrm{C}$ for $20 \mathrm{~min}$ or if it was mixed with $\mathrm{I} \cdot 0 \%(\mathrm{w} / \mathrm{v})$ Suramin, a known lysozyme inhibitor (Lominski \& Gray, 196I).

The chain-disrupting factor in SF did not cause cell separation but disrupted chains by causing a slow lysis of cells randomly distributed within long chains of the $S$. faecalis NCTC2400. There was no apparent change after 20 min exposure to SF, but after 30 min the initial stage of disruption was evident. Further new sites of attack were seen as incubation continued (Fig. I). There was no such disruption of the long chains by SF which had been heated at $100{ }^{\circ} \mathrm{C}$ for $20 \mathrm{~min}$. The chain-disrupting activity of the culture supernate fractions increased during the period of exponential growth, suggesting that the active constituent might be an autolysin.

Fan (1970 $a, b)$ showed that an autolysin L of Bacillus subtilis caused dechaining of long filaments, and suggested that it cleaved the peptide side-chains from the polysaccharide strands of the peptidoglycan thus causing cell separation. However, it is possible that a time sequence examination of this process might reveal lysis of cells within the filament as shown here with $S$. faecalis.

\section{REFERENCES}

Chatterjee, A. N., Mirelman, D., Singer, H. J. \& Park, J. T. (1969) Properties of a novel pleiotropic bacteriophage-resistant mutant of Staphylococcus aureus H. Journal of Bacteriology 100, 846-853.

FAN, D. P. (1970a). Cell wall binding properties of the Bacillus subtilis autolysin(s). Journal of Bacteriology 103, 488-493.

FAN, D. P. (1970b). Autolysin(s) of Bacillus subtilis as dechaining enzyme. Journal of Bacteriology 103, 494499.

Higgins, M. L., Pooley, H. M. \& Shockman, G. D. (1970). Site of initiation of cellular autolysis in Streptococcus faecalis as seen by electron microscopy. Journal of Bacteriology 103, 504-512.

LOMINSKI, I., CAMERON, J. \& WYLLIE, G. (I958). Chaining and unchaining Streptococcus faecalis - a hypothesis of the mechanism of bacterial cell separation. Nature, London 181, I477.

LOMINSKI, I. \& GraY, S. (196I). Inhibition of lysozyme by Suramin. Nature, London 192, 683.

Pooley, H. M. \& ShockmaN, G. D. (1970). Relationship between the location of autolysin, cell wall synthesis, and development of resistance to cellular autolysis in Streptococcus faecalis after inhibition of protein synthesis. Journal of Bacteriology ro3, 457-466.

Shockman, G. D., Pooley, H. M. \& Thompson, J. S. (1967). Autolytic enzyme system of Streptococcus faecalis. III. Localization of the autolysin at the sites of cell wall synthesis. Journal of Bacteriology 94, I525-1530.

Shockman, G. D., Thompson, J. S. \& Conover, M. J. (1967). The autolytic enzyme system of Streptococcus faecalis. II. Partial characterization of the autolysin and its substrate. Biochemistry 6, I054-1065.

SOPER, J. W. \& WINTER, C. G. (I973). Role of cell wall autolysin in chain formation by a mutant strain of Streptococcus faecalis. Biochimica et biophysica acta 297, 333-342.

Toennies, G., Iszard, L., Rogers, N. B. \& Shockman, G. D. (I96I). Cell multiplication studied with an electronic particle counter. Journal of Bacteriology 82, 857-866.

TomASz, A. (1968). Biological consequences of the replacement of choline by ethanolamine in the cell wall of pneumococcus : chain formation, loss of transformability and loss of autolysis. Proceedings of the National Academy of Sciences of the United States of America 59, 86-93. 